\title{
Seismic Vulnerability and Insurance Studies *
}

\author{
by Auguste C. Boissonnade ${ }^{* *}$ and Haresh C. Shah ${ }^{* * *}$
}

\section{Introduction - Risk identification}

Seismic risk is defined as the likelihood of loss and involves four basic components (Figure 1.1).

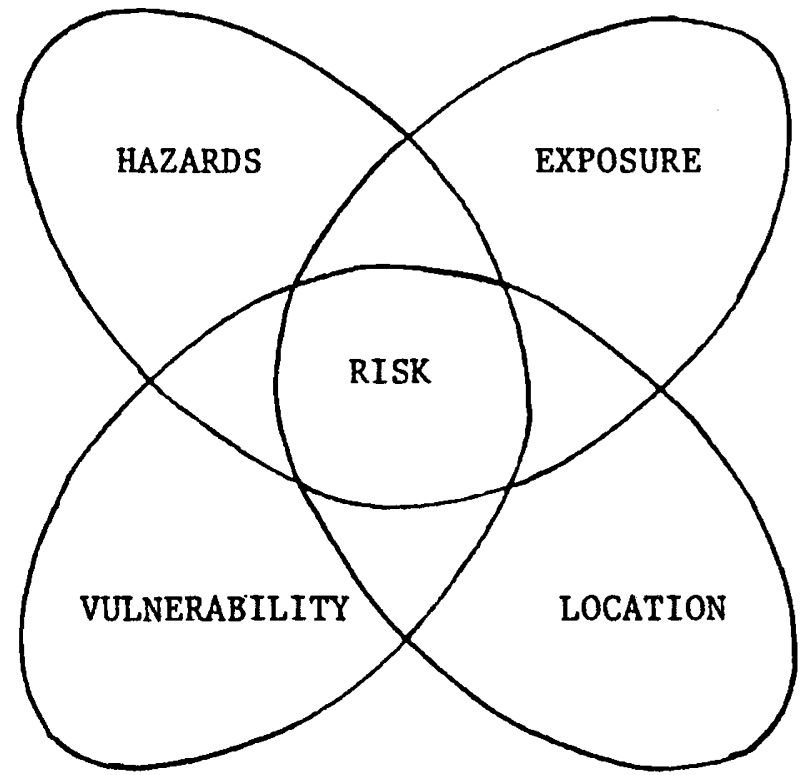

Figure 1.1: Risk estimation

* This work was partially supported by the National Science Foundation under Grant No. NSF-PFR-80-17533 and the John A. Blume Earthquake Engineering Center, Stanford University, Stanford, CA, USA.

** Post doctoral Research Fellow ; The John A. Blume Earthquake Engineering Center, Stanford University, CA, USA.

*** Professor of Structural Engineering ; Director, The John A. Blume Earthquake Engineering Center, Stanford University, California, USA. 
1. The hazards or dangerous situations may be classified as :

- primary hazards (fault break, ground vibration);

- secondary hazards which are potential dangerous situations triggered by the primary hazards. For example, a fault break can cause a Tsunami or ground shaking can result in foundation settlement, foundation failure, liquefaction, landslides, etc. ;

- tertiary hazards produced by flooding by dam break, fire following an earthquake and alike.

All these hazards lead to damage and losses (Figure 1.2). They may be expressed in terms of severity, frequency and location.

2. The exposure is defined as the value of the structures and contents, business interruption, lives, etc.

3. The vulnerability is defined as the sensitivity of the exposure to the hazard(s) and the location relative to the hazard(s).

4. The location is defined as the position of the exposure relative to the hazard.

Losses resulting from seismic hazard are numerous and can be categorized as :

1. life and injury ;

2. property ;

3. business interruption ;

4. lost opportunities ;

5. contents ;

6. tax base ;

7. etc.

Three types of losses can be identified (Figure 1.3). These losses can impact various types of insurance coverages (structural damage, fire, business interruption, ...).

The earthquake loss evaluation methods may be probabilistic or deterministic (Figure 1.4 and 1.5). Each method differs according to the objectives (types of losses to be estimated).

A seismic risk analysis needs the identification of the losses to be studied as stated above but also the identification of the hazards, exposures and their locations, and vulnerability.

Some methods of hazard identification are :

1. macrozonation maps (with or without soil effects) ;

2. microzonation maps (with or without soil effects) ;

3. fault maps ;

4. quake/intensity site specific;

5. etc.

Exposure identification is strongly related to the types of losses investigated. A Risk analysis of the buildings (structures) needs to identify all buildings and their values susceptible to be affected by ground shaking and other hazards. However, loss of business income will result in a combination of damage to several exposures such as economic losses from property damage, interruption in transportation, lives lost and alike. Figure 1.6 illustrates the chain of events which can occur. 


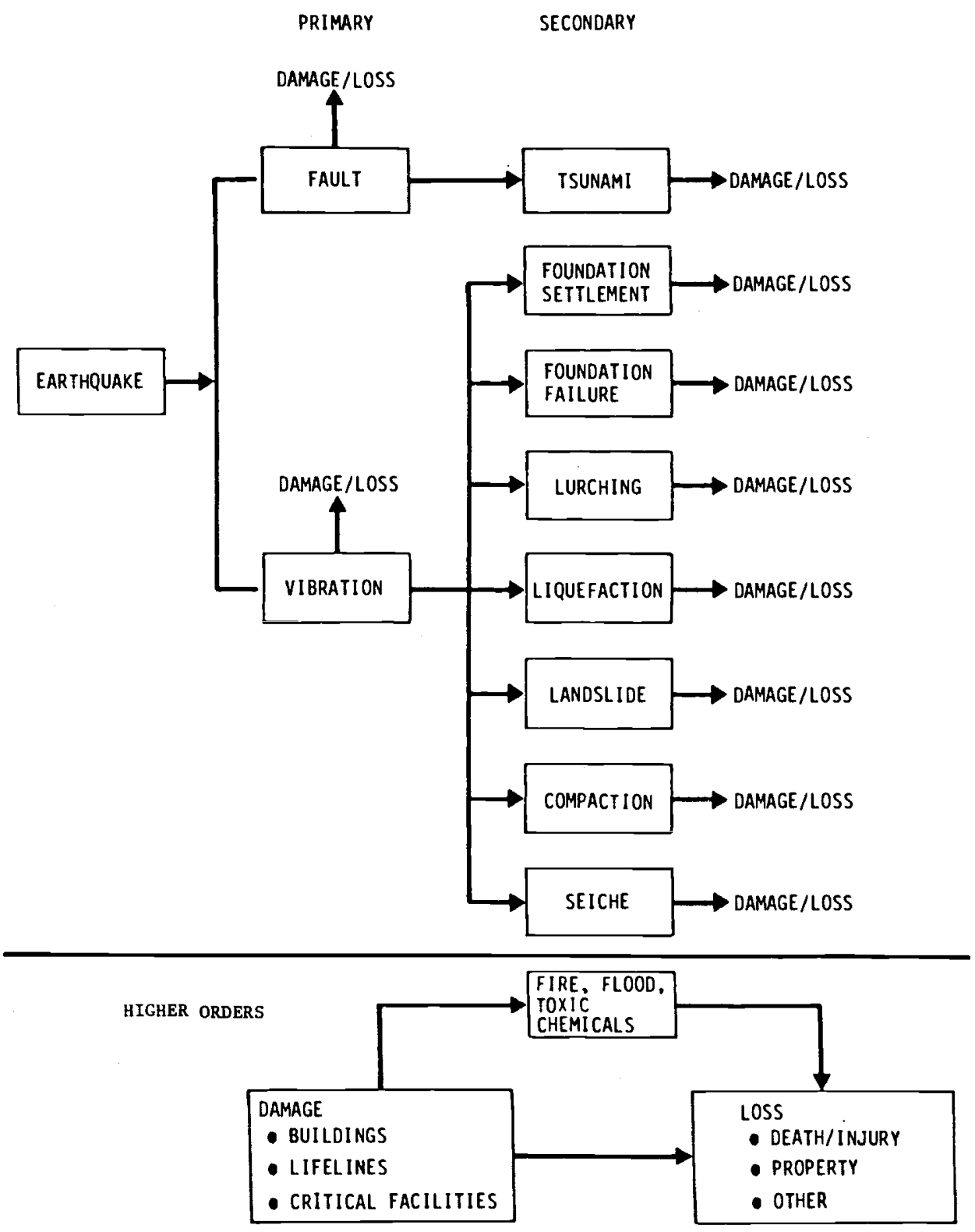

Figure 1.2: Primary, secondary and higher order earthquake hazards leading to damage and losses (from Wiggins [1981]) 


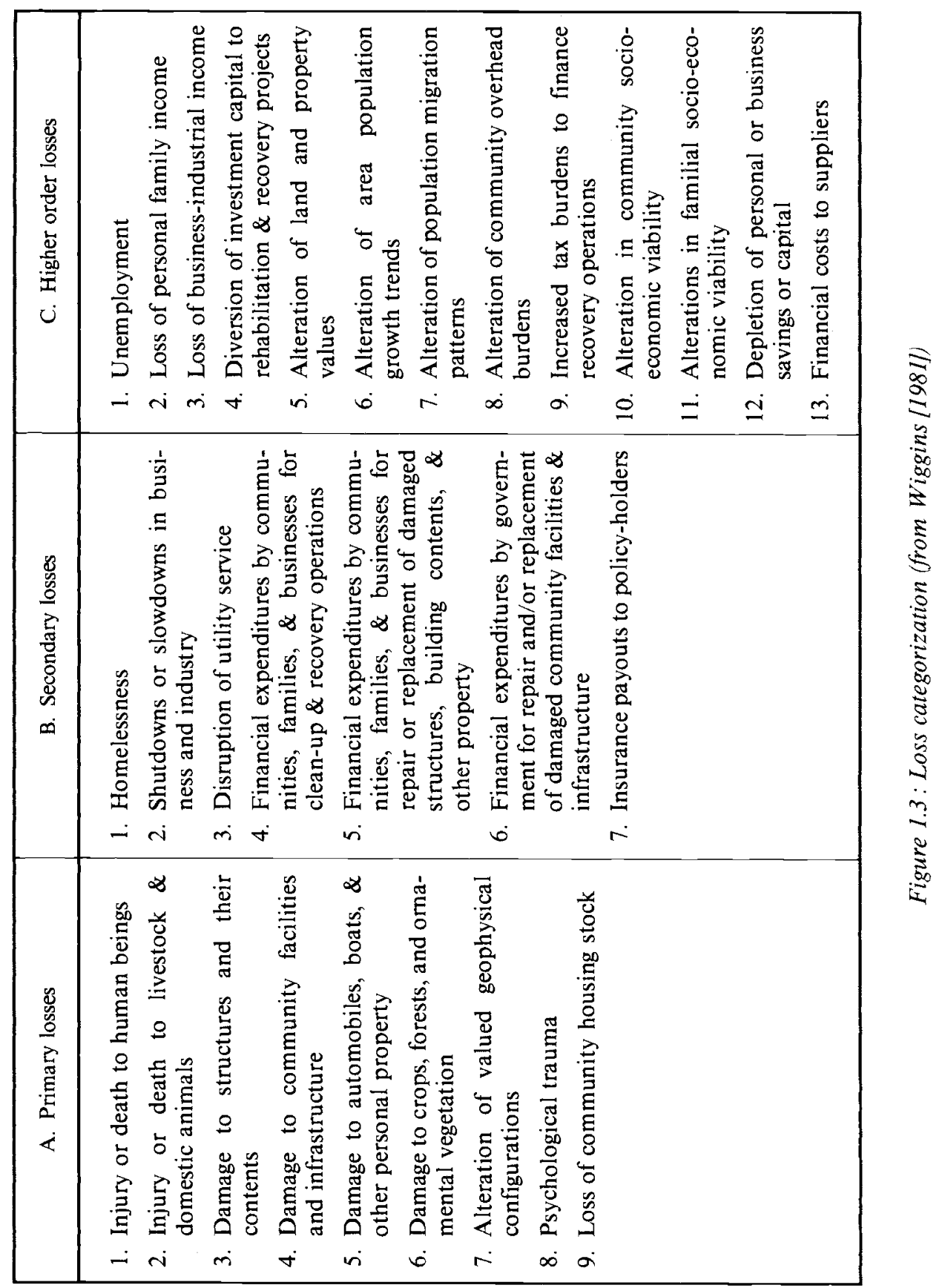



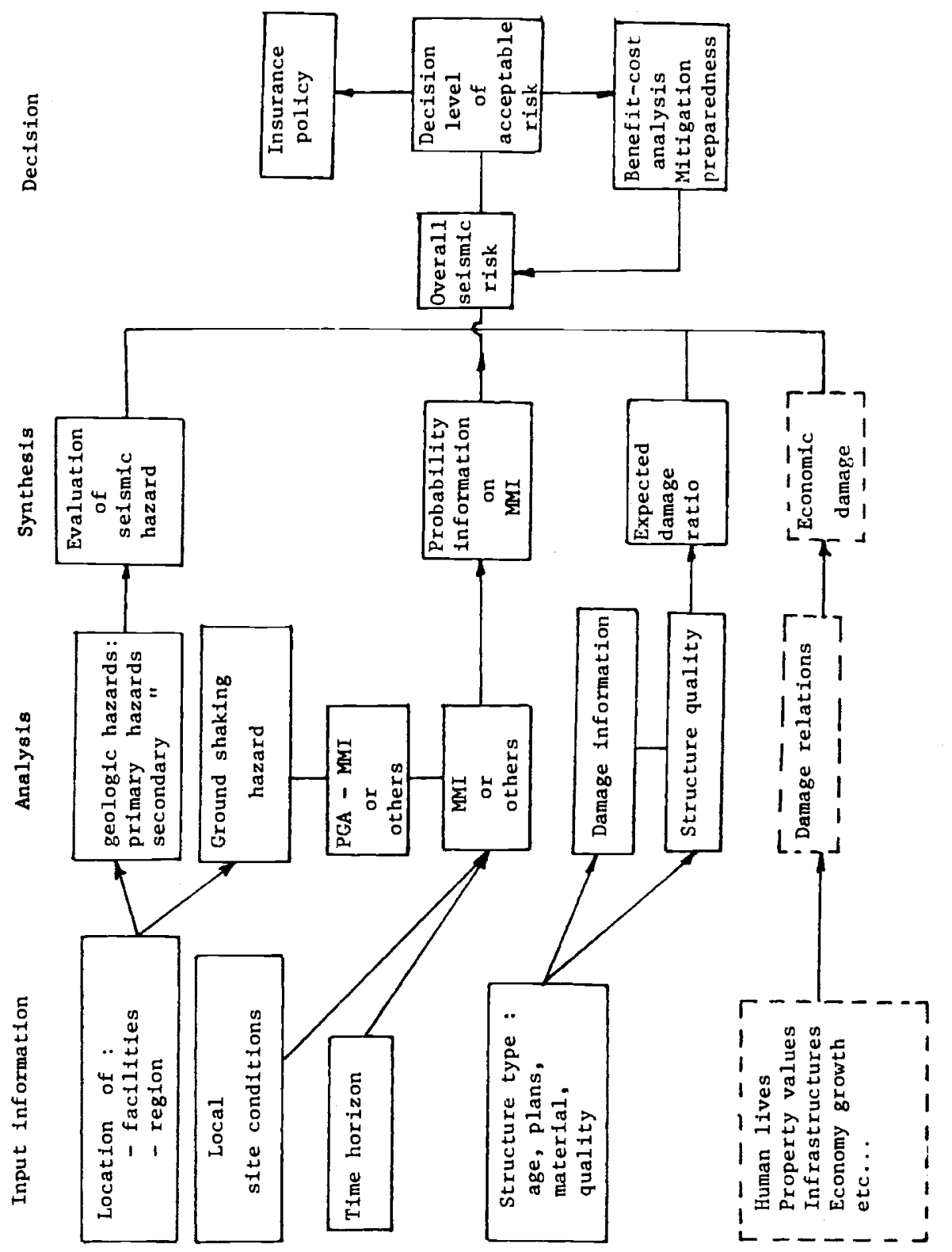


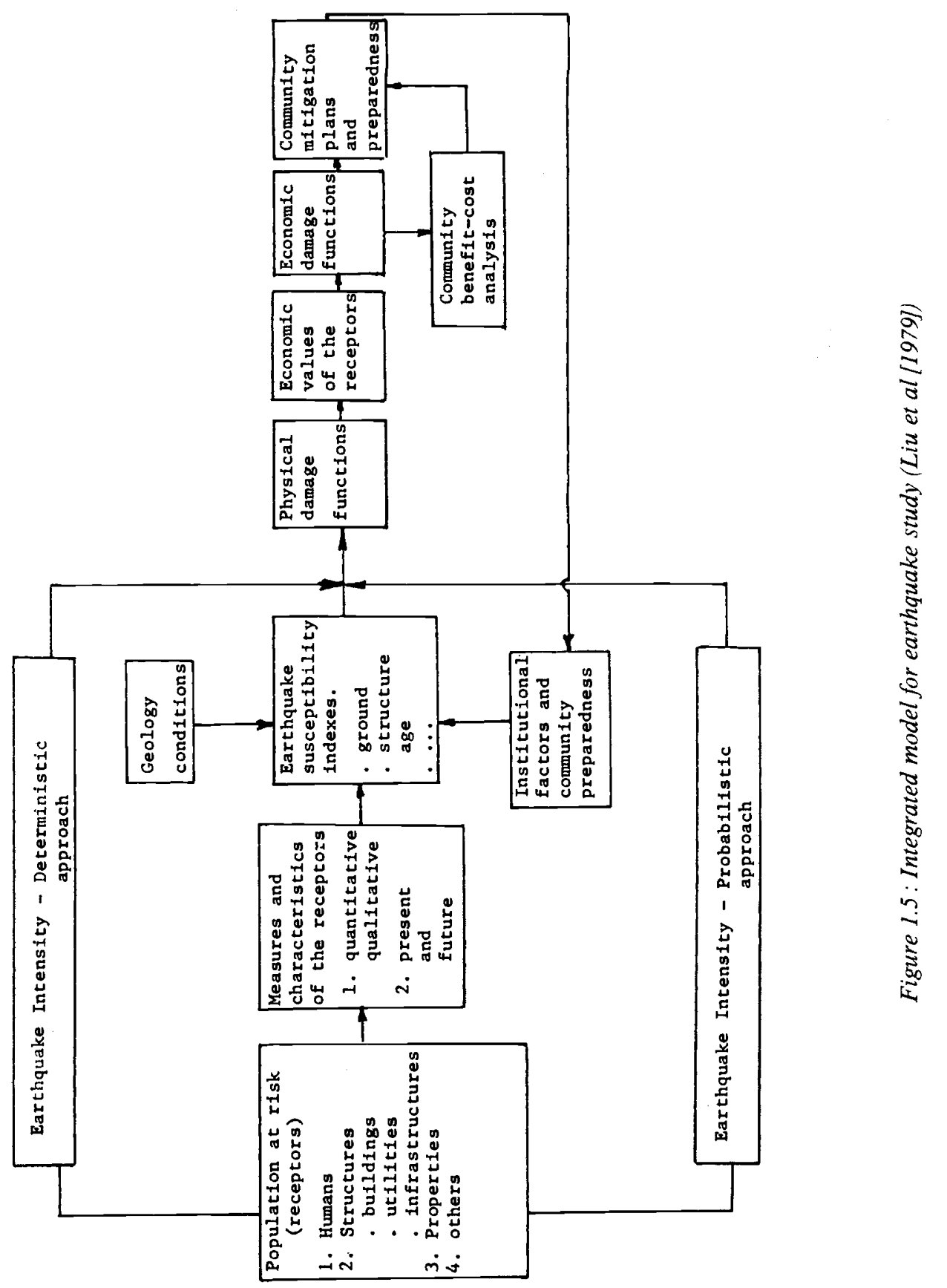




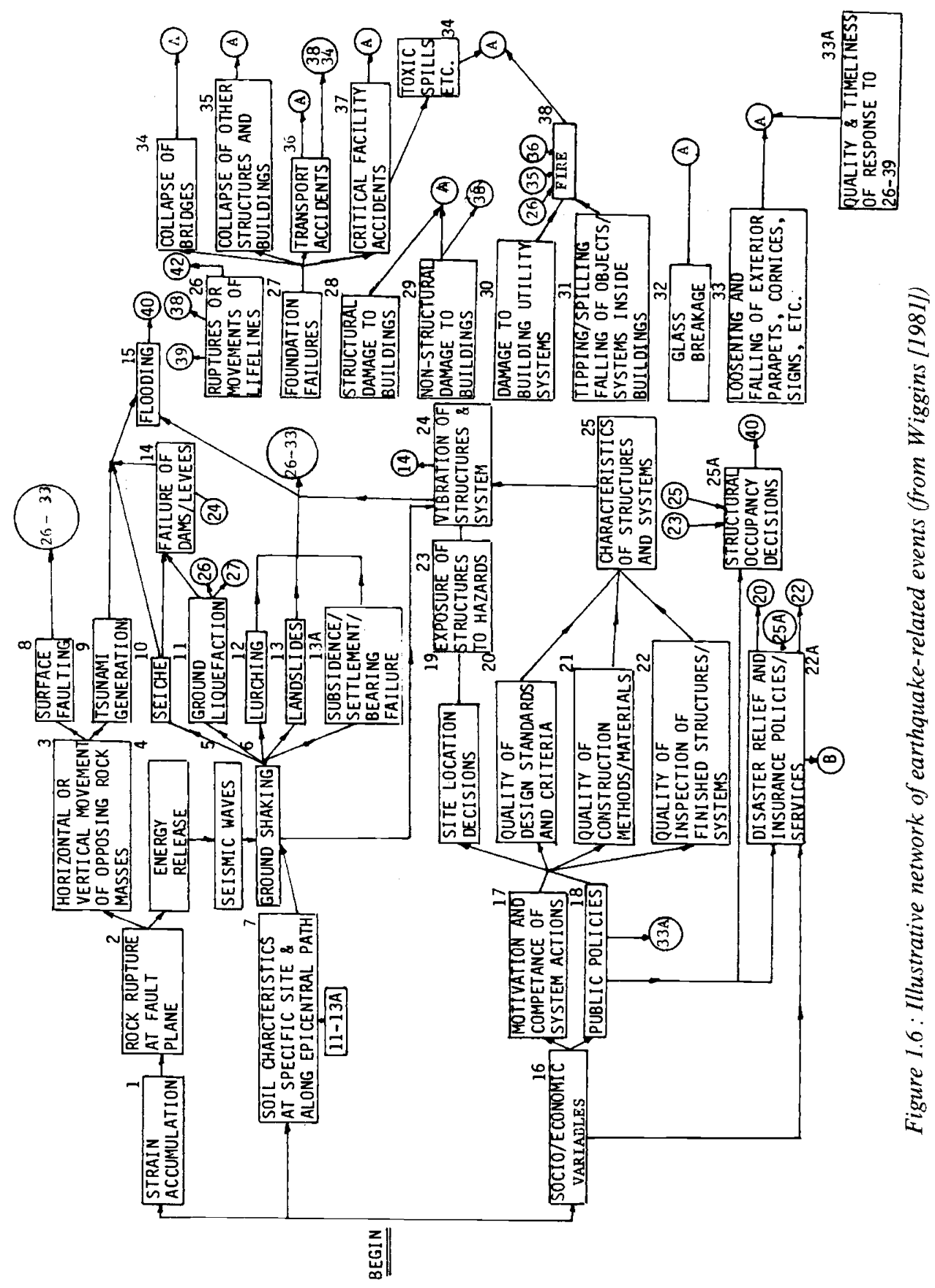




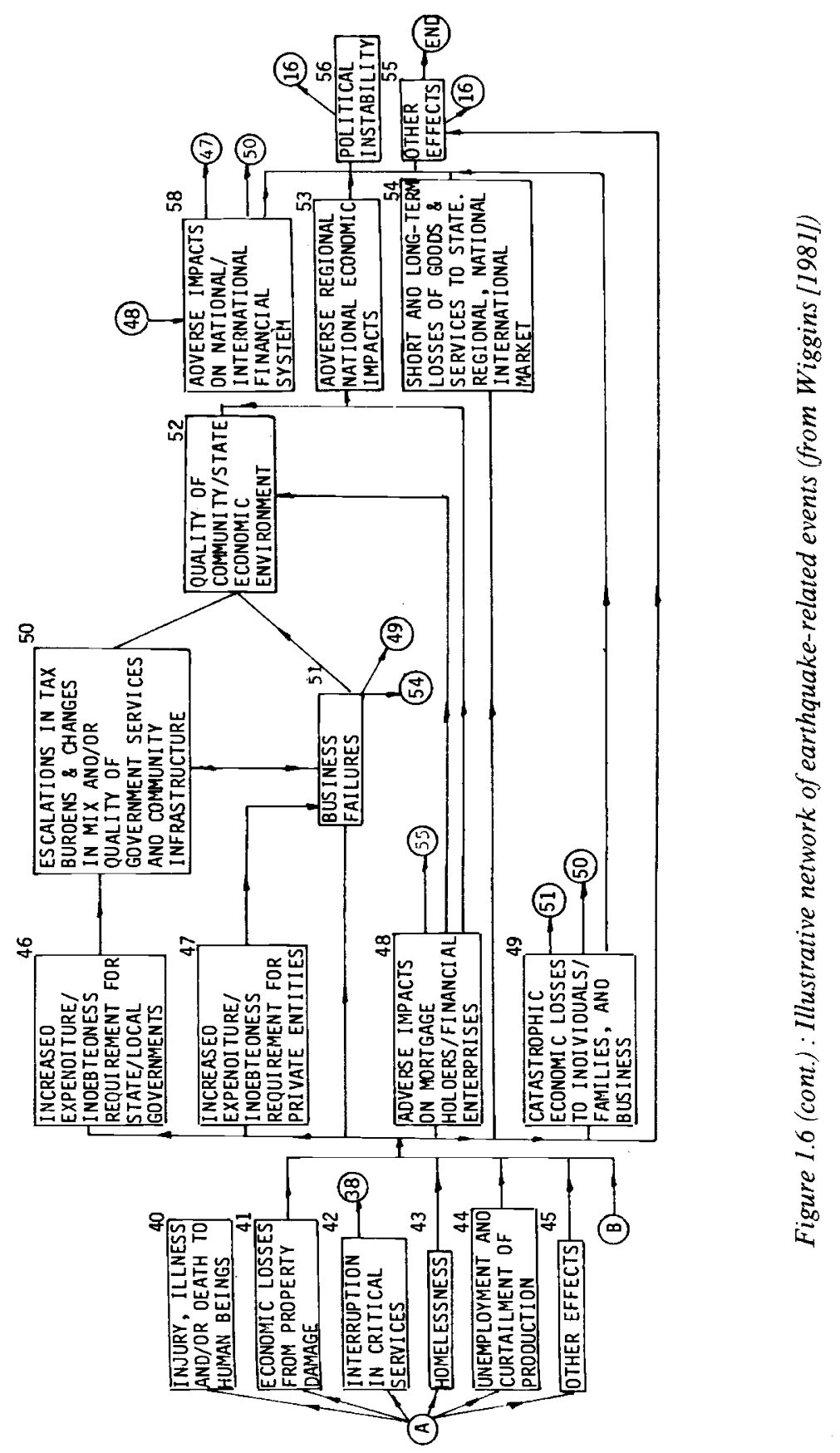


In the following are some examples of different types of exposures with their particular classifications (taken from Wiggins [1981]).

\section{Buildings}

- framing systems ;

- floors and roofs ;

- elevated tanks, towers, chimneys ;

- ornamentation - parapets ;

- connections ;

- fixtures ;

- walls, shear walls ;

- piles ;

- etc.

Water supply and distribution

- dams;

- tunnels ;

- pipes (elevated, underground) ;

- treatment plants;

- pumping stations

- tanks ;

- etc.

Power systems

- generating stations;

- transmission lines;

- distribution lines;

- communication and power control ;

- warehouses ;

- fuel handling facilities;

- oil and gas pipelines, storage tanks ;

- etc.

Transportation systems

- air terminals, radio communications, etc. ;

- sea terminals ;

- land highway, street, roads, railroads, bridges, tunnels 
A risk analysis must consider the applicable hazards, the vulnerability analysis procedures as well as the required data on hazards and the structure characteristics.

In the following sections, buildings are treated as exposures and some vulnerability analyses will be presented. A review of the available methods to estimate losses and premiums will be presented and a general methodology will be discussed where it can be shown that a probabilistic model may treat the uncertainties involved in such a study.

\section{Earthquake insurance (1932-1934)}

Earthquake insurance coverage has been marketed by American insurance companies since at least the 1910's. However it has never been widely purchased. One reason is the potential policy holders did not feel worthy the need to invest each year in an insurance to cover damage to their properties in case of a major earthquake of which the possibility of occurrence seemed remote. On the other hand insurance companies did not promote this type of coverage for fear of excessive losses.

One of the earliest studies to show, that the earthquake insurance is feasible, if a systematic approach is used, was done by Freeman [1932]. He classified the structures relevant to their behavior to earthquake ground shaking and estimated their expected loss ratios for large earthquakes. Premiums could be computed based on this information.

A comprehensive discussion of factors involved in determining premium rates (and expected losses) is presented by Chick [1934] where he considered :

1. frequency of occurrence of earthquakes in any particular region;

2. expected loss ratio for different types of construction ;

3. the amount of insurance coverage in relation to the value of the structure ;

4. underwriting expenses;

5. factor of safety ;

6. reserves.

The expected loss ratios were given for a severe earthquake, from past data, and with a range on the losses. Several factors were considered in the estimation of losses such as :

- ground characteristics ;

- location of faults ;

- design and materials ;

- quality of materials and workmanship.

The amount of insurance premiums were considered in relation to the deductibles and special considerations were taken on coverage of contents of buildings. The consideration of all these factors made possible the computation of yearly premiums. However many parameters were estimated by personal judgement.

Currently, insurance companies are using the same philosophy for computing yearly premiums but with more scientific background. However the judgement must still be used since our understanding of earthquake phenomenon and the mechanism of damage to structure shaken by ground motion is far from complete. 


\section{Earthquake insurance (1969 to present)}

From the 1930's to the 1960's, engineers have turned their efforts to understand the behavior of structures under dynamic loading. At the same time the theory of probability has been applied in Seismology and Earthquake Engineering.

In 1969, a large study related to potential damage to structures in California (Algermissen et al [1969], Steinbrugge et al. [1969]) investigated the seismicity and earthquake damage statistics of this earthquake prone region. The 1971 San Fernando earthquake was the starting point of research on damage evaluation and forecasting. Considerable information was collected afterwards for each major earthquake and numerous results are now available on seismic intensity and damage to structures. However, ignorance still exists on the seismic severity (usually expressed in intensity values) a site may expect in the future as well on the damage a structure may sustain for a given seismic intensity. This has to be incorporated in any earthquake insurance coverage.

Two major problems in earthquake insurance have to be solved: the premium computations and the solvency estimation in case of large aggregate losses.

\subsection{Premium estimation for an individual structure}

Loss estimation reported per year has to be computed for establishing yearly premiums. The basic formula for estimating the expected losses per year is :

$$
E L_{1}=\sum_{I}(D R / I) V \mu_{I}
$$

where :

$E L_{1}$ : expected losses per year.

$D R / I$ : mean damage ratio for a given intensity $I$.

$V$ : value of the building (monetary value).

$\mu_{I}$ : mean occurrence of event of intensity $I$.

$$
\mu_{i}=\frac{1}{R P_{i}} \text { with } R P_{i} \text { the corresponding return period. }
$$

Equation (1) may be expressed in percentage of the value of the building so :

$$
E L_{1}=E(D R)_{1} V
$$

with $E(D R)$, the expected value of the damage ratio per year and

$$
E(D R)_{1}=\sum_{T} D R / I \mu_{I}
$$

Equation (2) may be written, for a coverage of $t$ years as :

$$
E(D R)_{t}=t\left[\sum_{I}\left(D R / T \mu_{l}\right]\right.
$$

Equation (3) is true as long as the return periods are many times longer than the insurance period and the rate of occurrence of earthquakes is constant over time.

Equations (1), (2) and (3) are good in theory but to be used, one has to believe in the values of $\mu_{I}$ and implicitly accept the notion that there are enough records to project the past into the future. This, in general, is not the case.

If one wishes to use these equations, confidence has to be introduced in the values $\left(\mu_{l}\right)$ by using a safety factor called $K_{\mu l}$. Then equation (2) can be written as : 


$$
E(D R)_{1}=\sum_{I}(D R / I) K_{\mu_{i}} \mu_{I}
$$

$K_{\mu I}$ may have different values for every mean occurrence value $\mu_{I}$.

The mean damage ratio $D R / I$ is obtained from statistical studies with large scatter, so this uncertainty must be considered by a factor $K_{D R / /}$. Moreover, $K_{D R / t}$ will change with intensity, so equation (4) may be rewritten as :

$$
E(D R)_{1}=\sum_{I}(D R / I) \mathrm{K}_{\mathrm{DR} / \mathrm{I}} \mu_{I} K_{\mu \mathrm{I}}
$$

For practical implementation, $K_{D R / I}$ and $K_{\mu I}$ are lumped together, $K_{I}=K_{D R / I} K_{\mu I}$ and we obtain :

$$
E(D R)_{1}=\sum_{T} K_{I}(\mathrm{DR} / \mathrm{I}) \mu_{I}
$$

The premiums per year, expressed in percentage of value of the structure can be estimated as :

$$
P_{1}=f\left[\sum_{T} K_{l}(D R / I) \mu_{t}\right]
$$

where $f$ is a factor covering deductions, costs, margin and profit of the company. This factor varies with each insurance company.

Finally, premiums are usually described as dollar amount per $\$ 1,000$ computed so as :

$$
G R=f \frac{V}{1000}\left(\sum_{I} K_{I}(D R / \Lambda) \mu_{I}\right)
$$

Example: A moment resisting steel space frame is designed and built in San Francisco. The structure was designed in accordance with the UBC 1973 code and is located on soft soil. Based on available seismic informations, a hazard model gives the seismic loading at the site in terms of $M M I$. A sensitivity analysis has been performed and a safety factor on $m_{I}\left(K_{\mu l}\right)$ has been assessed. Also a mean damage ratio versus intensity is available for this type of structure and a safety factor on $D R / I\left(K_{D R / I}\right)$ has been assessed by considering the special characteristics of this structure.

Table 3.1 shows the calculation of the expected value of the damage ratio per year as given in equations (2) and (6). The expected damage ratio (\%) will be $31.07 \%$ or $9.39 \%$, if there is or not the incorporation of a safety factor which is, in this example, of $3.31[31.07 / 9.39=3.31]$.

Although this case is not a real one, some trends reported here in the uncertainties are very general. For occurrence of events, the uncertainty increases with the severity of the ground shaking while for the vulnerability analysis it decreases as the mean damage ratio increases.

It is interesting to note in this example that large differences between columns 7 and 8 occur at low intensity. If we consider a $2 \%$ and $5 \%$ deductible respectively, the basic risk premiums would be :

- deductible $2 \%: 4.19 \%$ - $7.37 \%$ overall safety factor 1.76 ;

- deductible $5 \%: 3.23 \%$ - $5.66 \%$ overall safety factor 1.75 .

The overall safety factor has been reduced from 3.3 to 1.8 . This reduction might be greater for low seismicity region where large uncertainty exists on occurrence of moderate earthquakes.

As a final remark, let us consider the probable maximum loss for this building for an event of return period approximately of 300 years which corresponds to $\mu_{I}=0.003$. This 


\begin{tabular}{|c|c|c|c|c|c|c|c|c|c|}
\hline 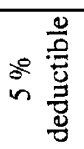 & $\begin{array}{l}\underset{x}{x} \\
\stackrel{=}{\|} \\
\simeq \\
\simeq\end{array}$ & 0 & 0 & $\stackrel{+}{\curvearrowleft}$ & $\stackrel{\infty}{\infty}$ & $\stackrel{\sim}{n}$ & $\bar{\Upsilon}$ & $\frac{2}{0}$ & $\begin{array}{l}8 \\
8 \\
0 \\
0 \\
\dot{0}\end{array}$ \\
\hline 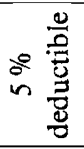 & $=$ & 0 & 0 & $\bar{n}$ & 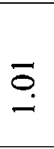 & $\frac{⿱ 亠}{r}$ & ô & $\begin{array}{l}\infty \\
+ \\
0 \\
0\end{array}$ & $\begin{array}{l}\stackrel{8}{0} \\
\stackrel{n}{n}\end{array}$ \\
\hline 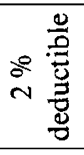 & $\begin{array}{l}0 \\
x \\
a \\
11 \\
0\end{array}$ & 0 & 0 & $\stackrel{g}{6}$ & $\frac{a}{i}$ & $\underset{+}{ \pm}$ & 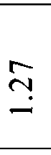 & $\stackrel{\infty}{2}$ & $\frac{8}{2}$ \\
\hline 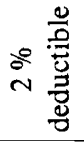 & $a$ & 0 & 0 & $\hat{a}$ & $\bar{\sim}$ & $\stackrel{\circ}{\infty}$ & $\stackrel{N}{\check{0}}$ & $\stackrel{q}{q} \cdot$ & $\frac{8}{\stackrel{8}{a}}$ \\
\hline 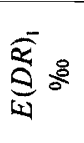 & $\underset{\infty}{\stackrel{0}{x}}$ & $\underset{\Xi}{\stackrel{\Xi}{\Xi}}$ & $\frac{\sim}{\sim}$ & $\begin{array}{l}\text { to } \\
i\end{array}$ & $\underset{\sim}{\stackrel{J}{\sim}}$ & $\bar{n}$ & $\stackrel{\text { ֻొ }}{=}$ & $\begin{array}{l}\infty \\
0 \\
0\end{array}$ & $\frac{8}{0}$ \\
\hline 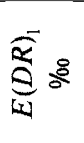 & $\begin{array}{l}\underset{x}{x} \\
\underset{\sim}{\|} \\
r\end{array}$ & $\stackrel{\sim}{\sim}$ & $\frac{ \pm}{i}$ & $\underset{\Xi}{\Xi}$ & $\stackrel{\Xi}{\longrightarrow}$ & 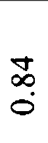 & $\frac{T}{\dot{0}}$ & ํ. & $\begin{array}{l}\stackrel{8}{0} \\
\grave{n} \\
\text { aे }\end{array}$ \\
\hline$\Sigma$ & $\begin{array}{c}n \\
\times \\
n \\
11\end{array}$ & $\stackrel{N}{N}$ & $\stackrel{\sim}{\sim}$ & $\stackrel{n}{\check{r}}$ & $\stackrel{\infty}{\infty}$ & $\stackrel{\infty}{-}$ & $\stackrel{0}{\check{2}}$ & $\stackrel{0}{-}$ & \\
\hline$v^{\alpha-a}$ & $n$ & 0 & $N$ & $\stackrel{\Xi}{\leftrightarrows}$ & $\stackrel{m}{-}$ & 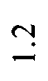 & 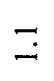 & $\stackrel{\circ}{-}$ & \\
\hline$\sum_{a} \circ$ & $\nabla$ & $\frac{\square}{0}$ & $\stackrel{n}{=}$ & 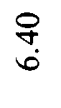 & $\stackrel{8}{8}$ & $\begin{array}{l}8 \\
\stackrel{8}{+}\end{array}$ & $\begin{array}{l}8 \\
\stackrel{+}{\pi}\end{array}$ & $\begin{array}{l}8 \\
\stackrel{8}{8}\end{array}$ & \\
\hline$z^{5}$ & $m$ & 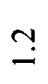 & $\stackrel{\Upsilon}{ }$ & $\stackrel{\overbrace{}}{\dddot{I}}$ & $\stackrel{\Xi}{-}$ & $\cong$ & $\stackrel{\circ}{\longrightarrow}$ & $\stackrel{0}{\longrightarrow}$ & \\
\hline$\Sigma$ & $\sim$ & $\stackrel{\dddot{g}}{=}$ & $\frac{n}{0}$ & $\begin{array}{l}\widetilde{N} \\
0 \\
0\end{array}$ & $\begin{array}{l}\overline{0} \\
8 \\
0 \\
0\end{array}$ & $\begin{array}{l}\bar{\delta} \\
\stackrel{\delta}{0}\end{array}$ & $\overline{8}$ & $\begin{array}{l}0 \\
\delta \\
\varnothing\end{array}$ & \\
\hline$\stackrel{\xi}{\Sigma}$ & - & 5 & $\overline{7}$ & $\Xi$ & $x$ & $x$ & $\bar{x}$ & $\bar{x}$ & \\
\hline
\end{tabular}


value corresponds to an $M M I=X\left(K_{\mu I} \mu I=1.5 \times 0.0021=0.0032\right.$ is $R P=320$ years $)$. For $M M I=X$ the mean damage ratio is $48 \%$ or $40 \%$ without the safety factor of 1.2 and corresponds to an expected damage ratio with $5 \%$ deductible of $0.74 \%$ or $1.32 \%$ $(7.4$ cents $/ \$ 100$ or 13.2 cents $/ \$ 100)$. These values are approximately four times less than the first calculated, so it is dangerous to estimate losses on a fraction of the seismicity of the area.

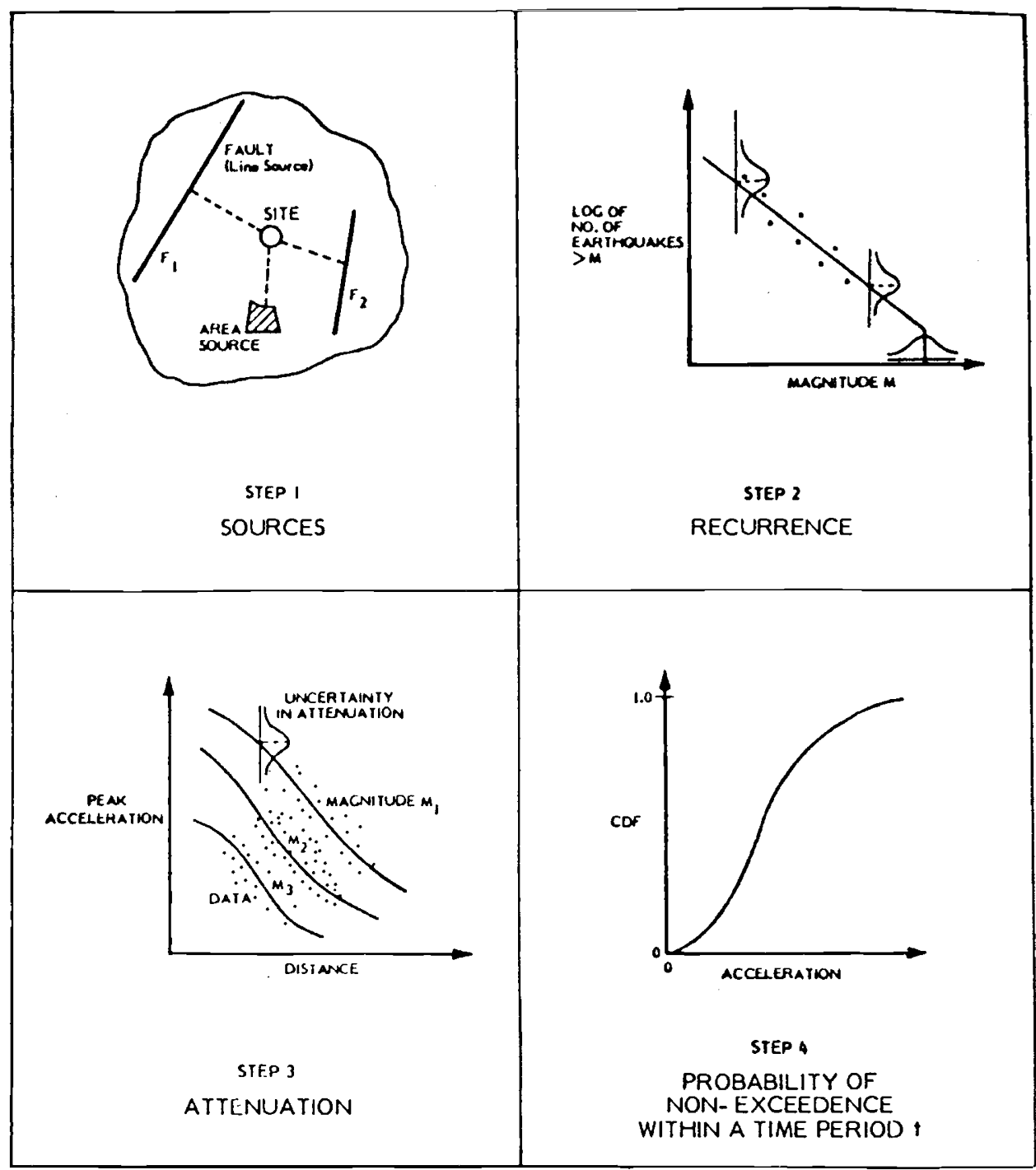

Figure 3.1 : Current approach to hazard mapping for peak values 


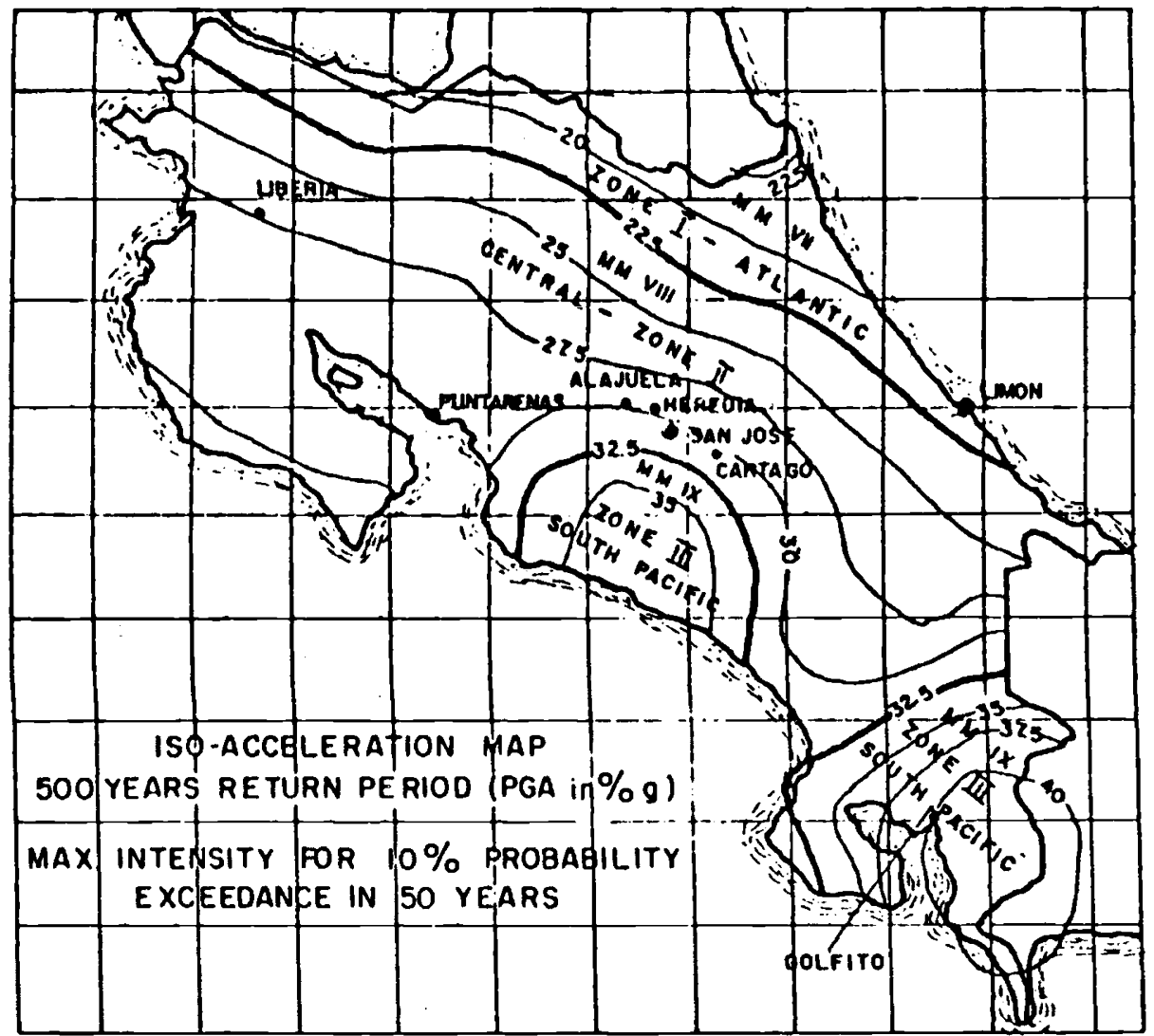

Figure 3.2: Costa Rica - Seismic zoning for insurance rating

\subsection{Premiums estimation for all types of structures}

In general it is more economical to estimate premiums for a whole class of structures based on macroseismic hazard analysis than a case by case evaluation of the seismic risk. This is particularly true for low valued buildings.

The following presents a procedure (Sauter and Shah [1978]) to evaluate premiums based on a macroseismic hazard analysis.

a) A seismic hazard analysis and isoacceleration or isointensity maps can be obtained for several return periods. Figures 3.1 and 3.2 present graphically the methodology and the results obtained. Zones with a fairly constant hazard intensity level can be delineated from the isointensity maps and then a unique loading recurrence relationship as shown in Figure 3.3 is representative of each region.

b) Average damage ratios are available and are represented in Figure 3.4. 


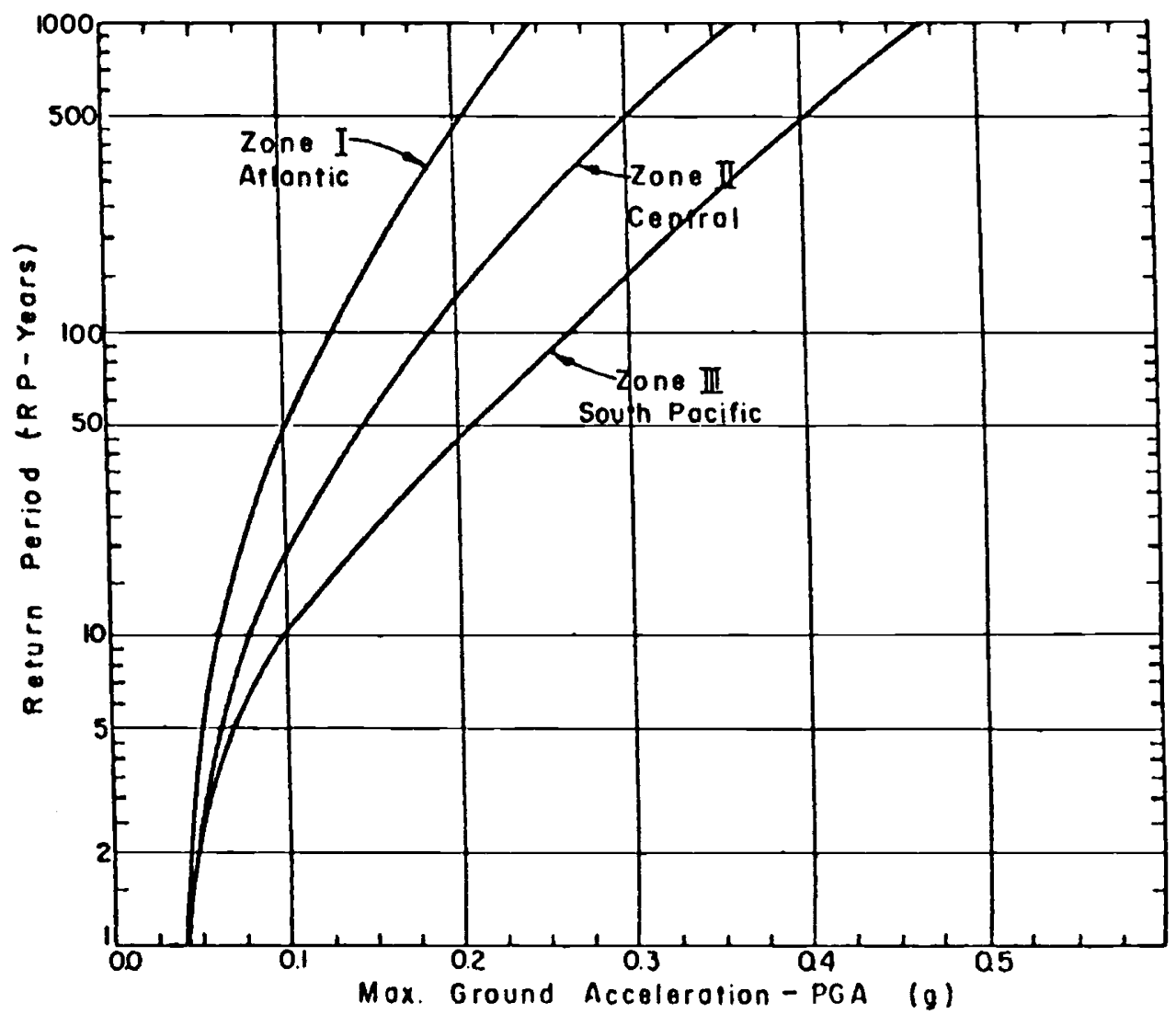

Figure 3.3: Return period vrs PGA relationships for Costa Rica (Sauter and Shah [1978])

c) Equation (2) may then be applied for each type of structure and for every region under consideration, so that :

(9) $\quad E(D R)_{\mathrm{l}, \mathrm{i}}=\sum_{I}(D R /)_{l} \mu_{I, j}$

where : $E(D R)_{l j, 1}$ : expected value of the damage ratio per year for structure class $l$ in zone $j$.

$(D R / I)_{l}$ : mean damage ratio of structure class $l$ for a given intensity.

$\mu_{I, j}$ : mean occurrence of event of intensity $I$ in zone $j$.

Formula (9) may be also written in order to account for uncertainty on recurrence of events and damage ratio as in equation (6):

$$
E(D R)_{l j, 1}=\sum_{I} K_{I, l j}(D R / I)_{l} \mu_{t, j}
$$

where : $\quad K_{I, l j}=K_{(D R / n) l} K_{\mu I, j}$ 
Average Damage vs Intensity (MMI)

Construction Types 1 to 10

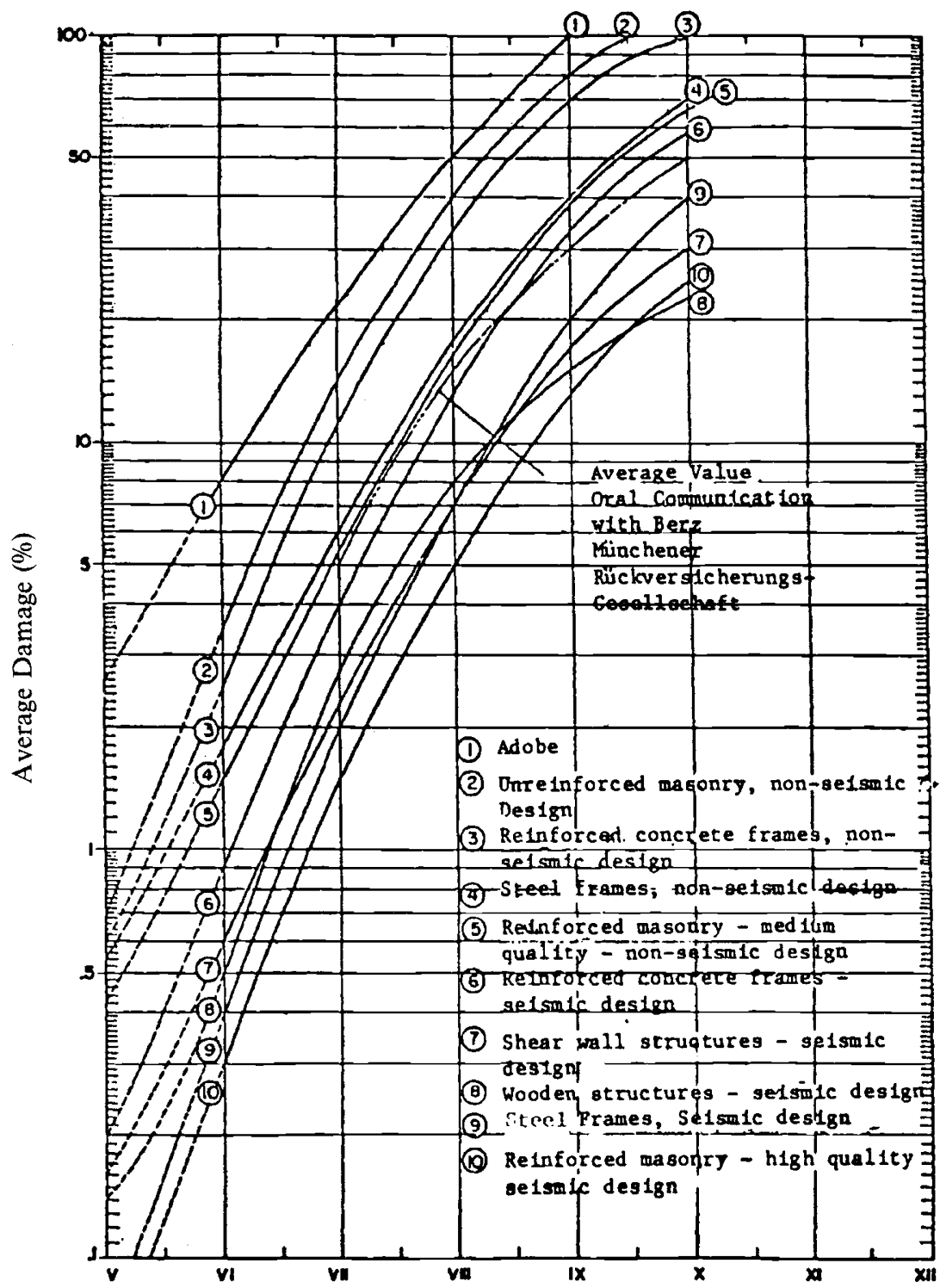

Figure 3.4 : Modified Mercalli Intensity (M.M.I.) (Sauter and Shah [1978]) 
Annual Premiums $P_{l j}$ can be computed from equations (9) and (10) for each class of structure and for every zone by introducing an appropriate factor $f_{l j}$ for a given class $l$ of structure, so :

$$
P_{l j}=f_{l j} E(D R)_{k j, 1}
$$

the factor $f_{l j}$ will take into account many factors, for example geologic hazards (liquefaction, landslides), exposure hazards from adjoining structures, unrepaired previous earthquake damage.

Example: Earthquake insurance premiums have to be computed for Costa Rica. From the results of the seismic hazard analysis, the country was divided into three zones for insurance rate assessment (Figure 3.2). This particular zoning is based on the relation

Table 3.2 (Zone II)

\begin{tabular}{|c|c|c|c|c|c|}
\hline $\begin{array}{c}P G A \\
\% \mathrm{~g}\end{array}$ & $\begin{array}{c}\text { Return } \\
\text { period } \\
\text { (years) }\end{array}$ & $\begin{array}{c}\text { Probability } \\
\text { Exceedance } \\
\text { (per year) }\end{array}$ & $\begin{array}{c}\text { Acceleration } \\
\text { Range } \\
\% \mathrm{~g}\end{array}$ & $\begin{array}{c}\text { Intensity } \\
M M I\end{array}$ & $\begin{array}{c}\text { Probability } \\
\text { occurrence } \\
\text { (per year) } \\
\mu_{I}\end{array}$ \\
\hline 4 & 1 & 1.000 & $<5$ & $<\mathrm{V}$ & 0.6000 \\
5 & 2.5 & 0.400 & $5-10$ & $\mathrm{VI}$ & 0.3444 \\
10 & 18 & 0.05556 & $10-20$ & VII & 0.04798 \\
20 & 132 & 0.00758 & $20-35$ & VIII & 0.0065 \\
35 & 900 & 0.00111 & $35-50$ & IX & 0.0009 \\
50 & 3800 & 0.00026 & $>50$ & $>\mathrm{X}$ & 0.00026 \\
\hline
\end{tabular}

for example $P(M M I=$ VII $)=0.005556-0.00758=0.04798$

The expected value of the damage ratio per year given by equation (9) can be computed, for example for reinforced concrete frames.

Table 3.3 (Reinforced Concrete Frames - Zone II)

\begin{tabular}{|c|c|c|c|c|c|}
\hline $\begin{array}{c}M M I \\
(1)\end{array}$ & $\begin{array}{c}\mu_{I} \\
(R)\end{array}$ & $\underset{\%}{D R / I}$ & $\begin{array}{c}E(D R)_{1} \\
\% \\
(4)=(2) \times(3) \times 10\end{array}$ & $\begin{array}{c}2 \% \\
\text { deductible }\end{array}$ & $\begin{array}{c}5 \% \\
\text { deductible }\end{array}$ \\
\hline$<\mathrm{V}$ & 0.600 & 0.2 & 1.2 & 0.0 & 0.0 \\
\hline VI & 0.3444 & 0.9 & 3.1 & 0.0 & 0.0 \\
\hline VII & 0.04798 & 4.0 & 1.919 & 0.96 & 0.0 \\
\hline VIII & 0.0065 & 13.0 & 0.84 & 0.71 & 0.52 \\
\hline IX & 0.0009 & 33.0 & 0.28 & 0.26 & 0.24 \\
\hline \multirow[t]{2}{*}{$>X$} & 0.00026 & 58.0 & 0.15 & 0.15 & 0.14 \\
\hline & & & $7.5 \%$ & $2.1 \%$ & $0.9 \%$ \\
\hline
\end{tabular}


of $P G A$ vs $M M I$ given in Table 3.2 and the probabilities of occurrence per year for the range of acceleration values defining the intensities from $M M I V$ to $X$ are calculated taking the difference of the probabilities of exceedance of each pair of successive values. Table 3.3 summarizes the results obtained for a reinforced concrete frame structure.

Considerations of uncertainties on the occurrence of events and on the estimates of damage can be included through the terms $K_{\mu I, j}$ and $K_{(D R / T)}$ as in Table 3.1.

Several remarks have to be noted at this point. First, the division of a seismic region into zones to apply uniform premiums (also called earthquake exposure zones) is based on the criterion of fairly constant hazard intensity level, such as the maximum intensity to be expected given a return period of 50 years or the maximum intensity for $10 \%$ probability exceedance in 50 years as in Figure 3.2, and second, a uniform distribution of the buildings (exposure) is assumed over the seismic region. Also probabilities of occurrence and damage ratios are far from definite so great importance rely on the estimation of the factor $K_{\mu l}$ and $K_{D R / T}$. Most often past experience and sound judgement will dictate the value to consider.

\subsection{Probable maximum loss}

Because large damaging earthquakes occur fairly infrequently, the premium amounts collected from earthquake insurance cannot be regarded as profits but rather they must be accumulated as reserves in the case of a catastrophic earthquake loss. So insurance companies must consider their overall risk for such events. This is done by dividing the earthquake risk areas into accumulation assessment zones where a probable maximum loss is calculated. The probable maximum loss can be seen as the most credible event occurring in the different zones with a corresponding return period. This is mainly a deterministic approach as seen in Figure 3.5.

Probable maximum loss dependent of the liabilities or exposure values together with the amount of premiums will be the base to decide which policy an insurance company would follow (excess of loss, protection, capacity, insurance policy, etc.). As pointed out by reinsurance companies (Munich Reinsurance Company [1976]), clear book keeping is essential so the risks can be evaluated clearly. Situations where earthquake coverages are included in non earthquake policies may greatly underestimate the probable maximum loss values.

\section{Earthquake risk insurance model - Uncertainties}

In the following section a risk model for earthquake premiums is presented. The uncertainties in this model are identified and treated at every step of the analysis. First, assume that there exists one type of structure (identical in every respect) uniformly distributed over a seismic region and the question is to define earthquake premiums for this particular type of structure. Two main problems have to be solved:

1. seismic hazard for the regions of interest, and

2. damage ratio versus the earthquake severity (vulnerability). 


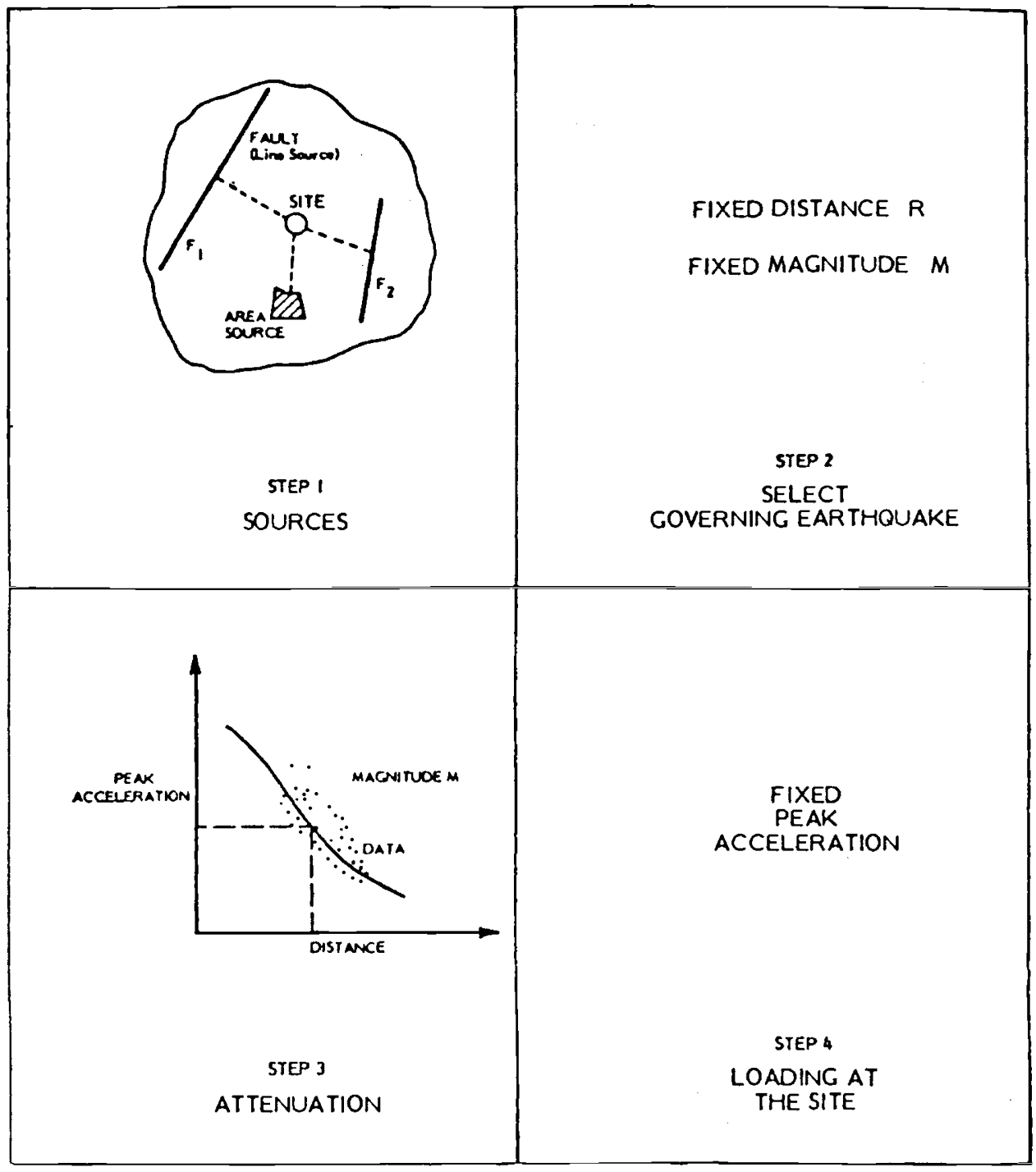

Figure 3.5: Deterministic approach to loading at the site

\subsection{Seismic hazard analysis (ground shaking)}

Much progress has been made during the last twenty years and reasonably good and rational models are now available for estimating earthquake loading at a site. However, great uncertainties still exist which have to be quantified. These uncertainties may be classified as : 
1. uncertainty on the occurrence and location of the future possible events ;

2. uncertainty on attenuation relationship from sites to sources.

The several necessary steps to estimate earthquake severity loading at a site are summarized in Figure 3.1. Let us take an example of a site where the estimation of the peak ground acceleration (as severity parameter) is needed. For the sake of simplicity, only one seismic source is assumed to affect the site under consideration. From past earthquake data, relations between earthquake occurrence and magnitude can be expressed in the well known formula :

$$
\log N(M)=a-b M(M<\operatorname{Max})
$$

where $N(M)$ is the number of earthquakes per year with magnitude greater than or equal to a given magnitude $M$. Uncertainties relevant to the scatter of data are considered in the determination of the coefficients $a$ and $b$. However such empirical formulation based on short historical earthquake data is insufficient. Newly developed information from physical and geological studies can now be incorporated by using Bayesian model or other inference methods as suggested by Dong and Shah [1983]. Figure 4.1 represents a schematic representation of the available information (historical data and other sources of information).

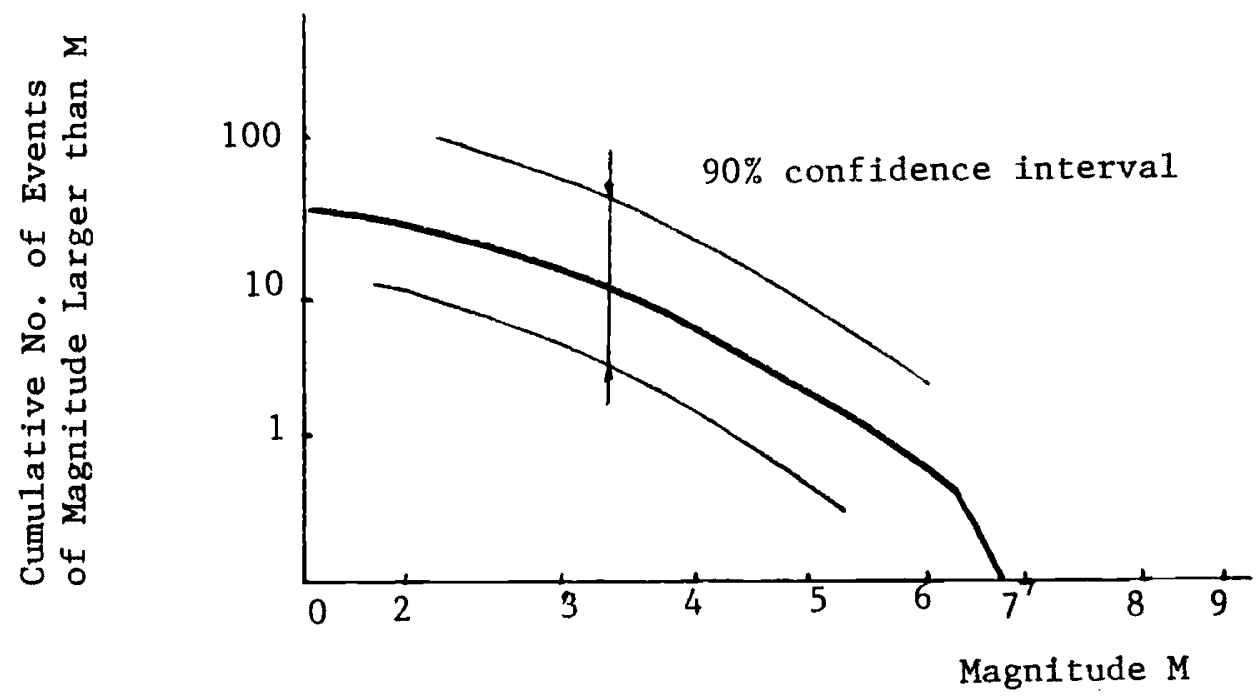

Figure 4.1

To obtain information on site intensity, ground motion attenuation relationships from the source to the site are needed. Many researchers have studied attenuations of different intensity parameters and considerable uncertainty exists in these relationships due to large scatter in the available data base. A general formula of these relationships is given as :

$$
A\left(\mathrm{~cm} / \mathrm{sec}^{2}\right)=a_{1} e^{b M}(R+C)^{-d}
$$


where $A$ is the maximum ground acceleration at a distance $R$ kilometers from a fault where an earthquake of Richter magnitude $M$ occurs, the coefficients $a, b, c$ and $c$ are dependent on the data and other characteristics of the earthquake mechanism such as the focal depth. Usually these attenuation relationships give the results of site intensity in the following form : given an event $M_{i}$ at the source, the probability of peak acceleration $A$ not exceeding some value is :

$$
P\left(A<a / M_{i}\right)=F\left(a / M_{i}\right)
$$

where $F(\cdot)$ is the conditional cumulative distribution function.

In future time $t$, if $n$ events occur with magnitude $x_{i}(i=1,2, \ldots r)$

then $P\left(A \geqslant a / x_{1}, \ldots x_{r}, n\right)=1-\prod_{i} F\left(a / x_{i}\right)$

and $P(A \geqslant a / n)=\underset{\text { all }}{x_{1}, \ldots x_{r}} \underset{P}{ } P\left(A \geqslant a / x_{1}, x_{2}, \ldots x_{r}, n\right) P\left(x_{1}, \ldots x_{r} / n\right)$

and finally the probability of exceeding in future time $t$ is :

$P(A \geqslant a)=\sum_{n=0}^{\infty} P(A \geqslant a / n) P_{t}(n)$

This method is very time consuming and simplified methods are generally used.

Uncertainty on the occurrence of earthquakes of different magnitudes as well as on attenuation relationships can be carried on to obtain a relation (Figure 4.2) between the probability of exceedance of a given acceleration level (return period) and the severity level (peak ground acceleration) with the overall uncertainty summarized in the confidence band. Figure 4.2 summarizes what is called "Probability risk analysis ". Often the number of uncertainties is so large that closed analytical expression is impossible. Simulation procedure is then needed to obtain upper and lower bound of such relationships.

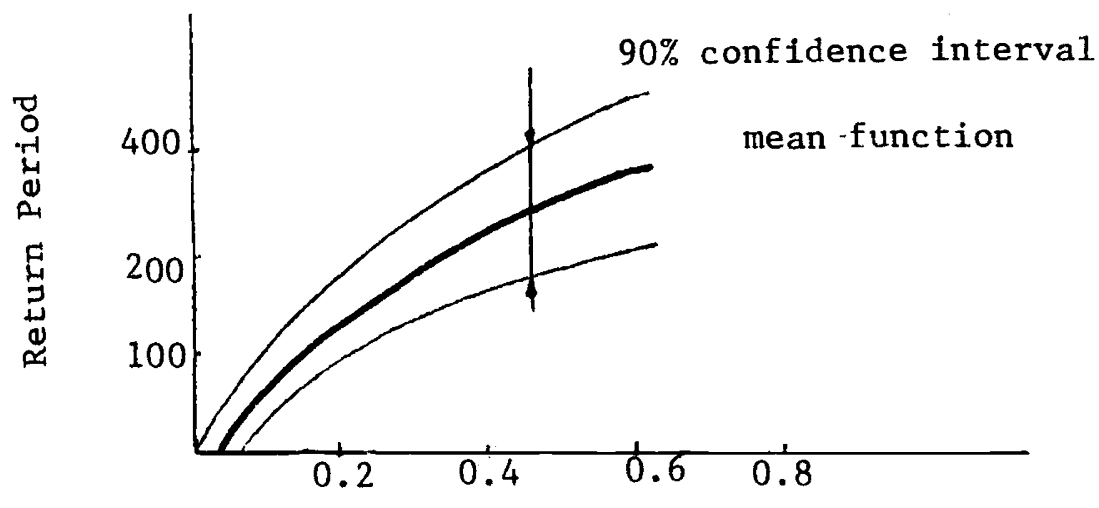

Peak Ground Acceleration (PGA) g-units

Figure 4.2 
The information on peak ground acceleration can be converted on $M M I$ values so relations as in Figure 4.2 can be derived with $M M i$ values for earthquake loading (Figure 4.3).

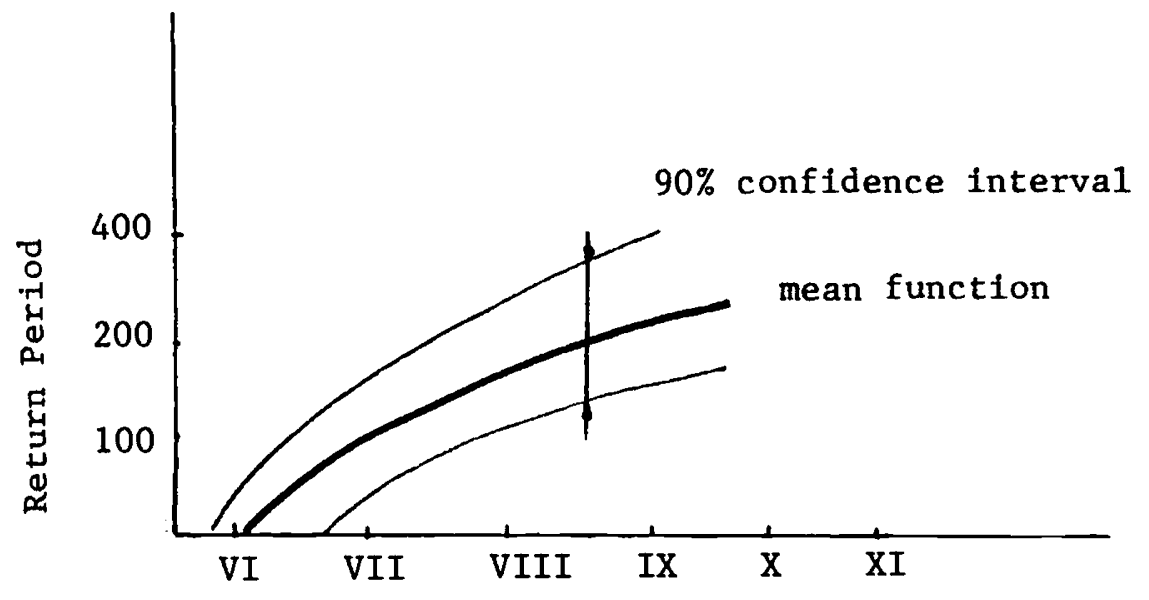

Modified Merca111 Intensity (MMI)

Figure 4.3

If several sources are affecting the site, similar studies are undergone and the loading of the site will be obtained by convolution of peak ground acceleration (intensity) due to the different sources.

\subsection{Vulnerability analysis (ground shaking)}

The methods presently available in vulnerability analysis to assess and/or forecast structural and non-structural damage can be classified with respect to the model used or the purpose of the analysis. Two groups of models can be distinguished: empirical and theoretical. Empirical models correlate ground motion intensity with a damage severity index (damage states or damage ratios) based on statistical observations of past events and very often from engineering judgement to supplement the insufficient data base. Theoretical models correlate ground motion intensity with response characteristics of a structure through analytical models and historical data.

In the case a valued structure has to be analyzed and its response to ground shaking predicted (insurance rating) a theoretical model may be appropriate. On the other hand, a class of structure such as low valued buildings often requires an empirical damage model. Both theoretical and empirical models exhibit large uncertainty and engineering judgement is needed. A schematic representation of the damage evaluation is shown in Figure 4.4 where the distributed values over a mean value are continuous. 


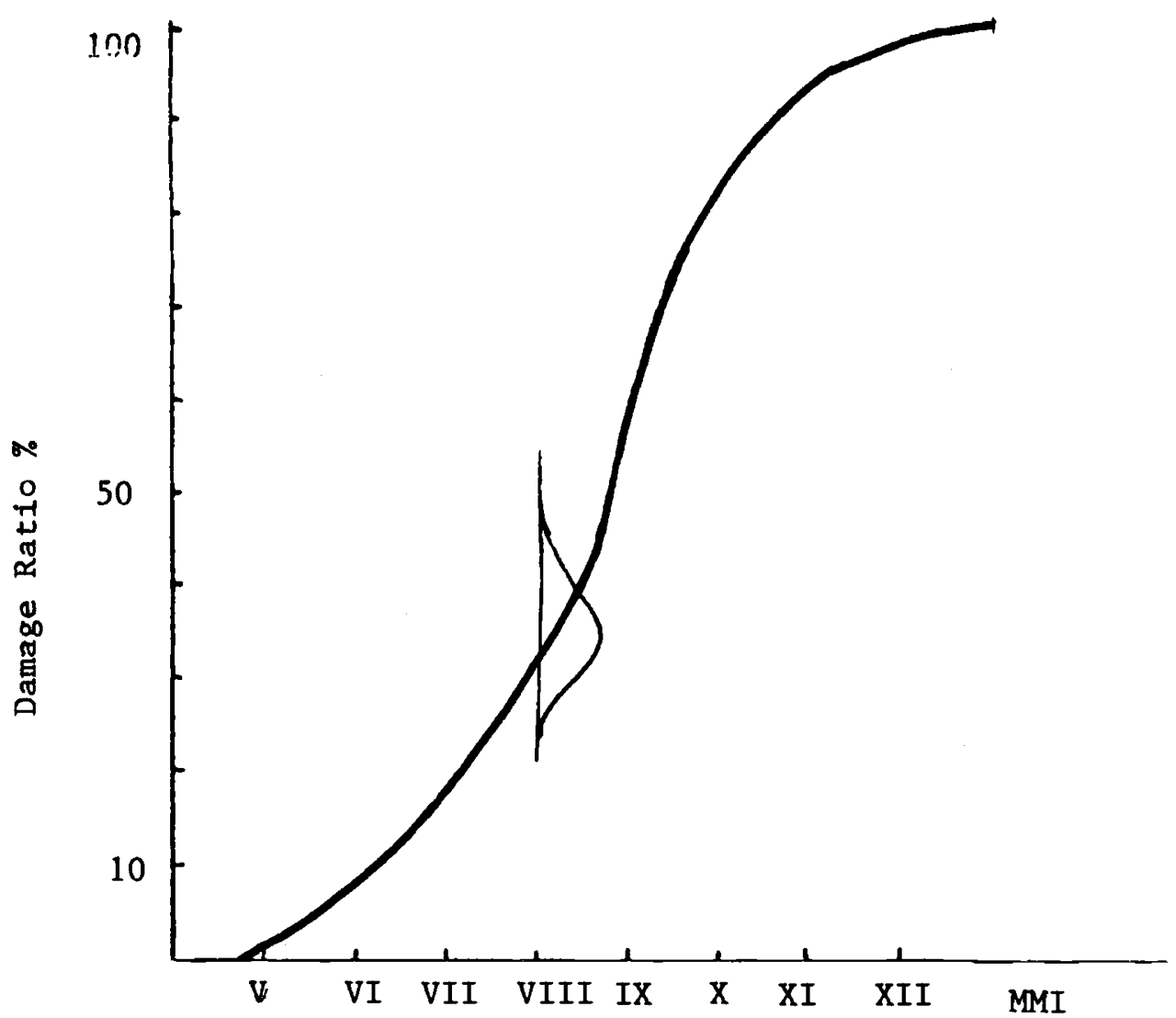

Figure 4.4

For practical reasons the distribution of the value of damage ratio over the mean value is discrete as well as the damage ratio $(D R)$ versus $M M I$ relationship. This information is represented by a damage probability matrix $[D P M]$ of which the colums represent the probability of damage for a given intensity and the rows the range of damage ratio. Table 4.1 is an example of such matrix. Each value of this matrix may also be interpreted as the number of buildings in a certain level of damage for a given intensity.

Damage ratios are usually given in terms of repair cost over replacement value (market value) and damage states are given in general terms such as (none, light, minor, severe, collapse). At this point it should be noted that a structure which has over $50 \%$ damage ratio is often considered unrepairable and it is more advantageous to tear it down and rebuild a new one. This point has to be considered in the final application of the vulnerability analysis. 
Table 4.1

\begin{tabular}{|c|c|c|c|c|c|c|c|}
\hline $\begin{array}{c}\text { Damage } \\
\text { Ratio } \\
\%\end{array}$ & \multicolumn{7}{|c|}{ MMI } \\
\cline { 2 - 8 } & VI & VII & VIII & IX & $\mathrm{X}$ & $\mathrm{XI}$ & $\mathrm{XII}$ \\
\hline 0 & 80 & 60 & 10 & 0 & 0 & 0 & 0 \\
10 & 10 & 30 & 50 & 10 & 0 & 0 & 0 \\
20 & 10 & 10 & 20 & 50 & 0 & 0 & 0 \\
$\cdot$ & $\cdot$ & $\cdot$ & $\cdot$ & $\cdot$ & $\cdot$ & $\cdot$ & $\cdot$ \\
$\cdot$ & $\cdot$ & $\cdot$ & $\cdot$ & $\cdot$ & $\cdot$ & $\cdot$ & $\cdot$ \\
\hline & $\cdot$ & $\cdot$ & $\cdot$ & $\cdot$ & $\cdot$ & $\cdot$ & $\cdot$ \\
100 & 0 & 0 & 0 & 2 & 20 & 100 & 100 \\
\hline
\end{tabular}

\subsection{Seismic risk (ground shaking - primary hazard)}

From the information provided in 4.1 on the seismic hazard of the site and the vulnerability analysis in 4.2 it is possible to estimate the yearly probability of damage for a given damage level.

Let Figure 4.3 be represented by a vector probability [ $I$ which lists the yearly probabilities of occurrence of the ground loading $(M M I)$ and that for the mean value, upper and lower bound.

The matrix product $[D P M] \times[\Pi]$ will give the yearly probability of a given damage ratio (state). The result may be summarized in Figure 4.5 where the seismic risk at the site is given in a continuous form. Figure 4.5 will permit to calculate the expected value of the damage ratio per year as described in sections 3.1 and 3.2.

Also seismic risk maps can be obtained for a seismic region. Those maps will show the isodamage curves for given return periods, such as in Figure 4.6 when the mean value is given. Similar maps can be derived from upper and lower bound of the confidence interval. The particular point of this type of maps is that the confidence level is identical at any point.

\subsection{Seismic risk (secondary hazard)}

As stated in the introduction, earthquake losses may be caused by different types of hazards. So far we have discussed only a primary hazard - ground shaking. Secondary hazards such as liquefaction, landslides, Tsunami and alike are also of interest in a damage estimation, particularly if they are covered in earthquake insurance.

Technical reports on landslides usually rate the potential for landsliding as very high, high and moderate. Curves correlating probability of a landslide given the peak ground acceleration and the landslide potential of the slope can be grossly assessed. In a damage assessment approach, the probability of occurrence of a landslide can be interpreted as the percentage of the slope area affected by landslide and the same percentage of buildings located in this area will be assumed to suffer landslide damage. As an example, for a PGA 


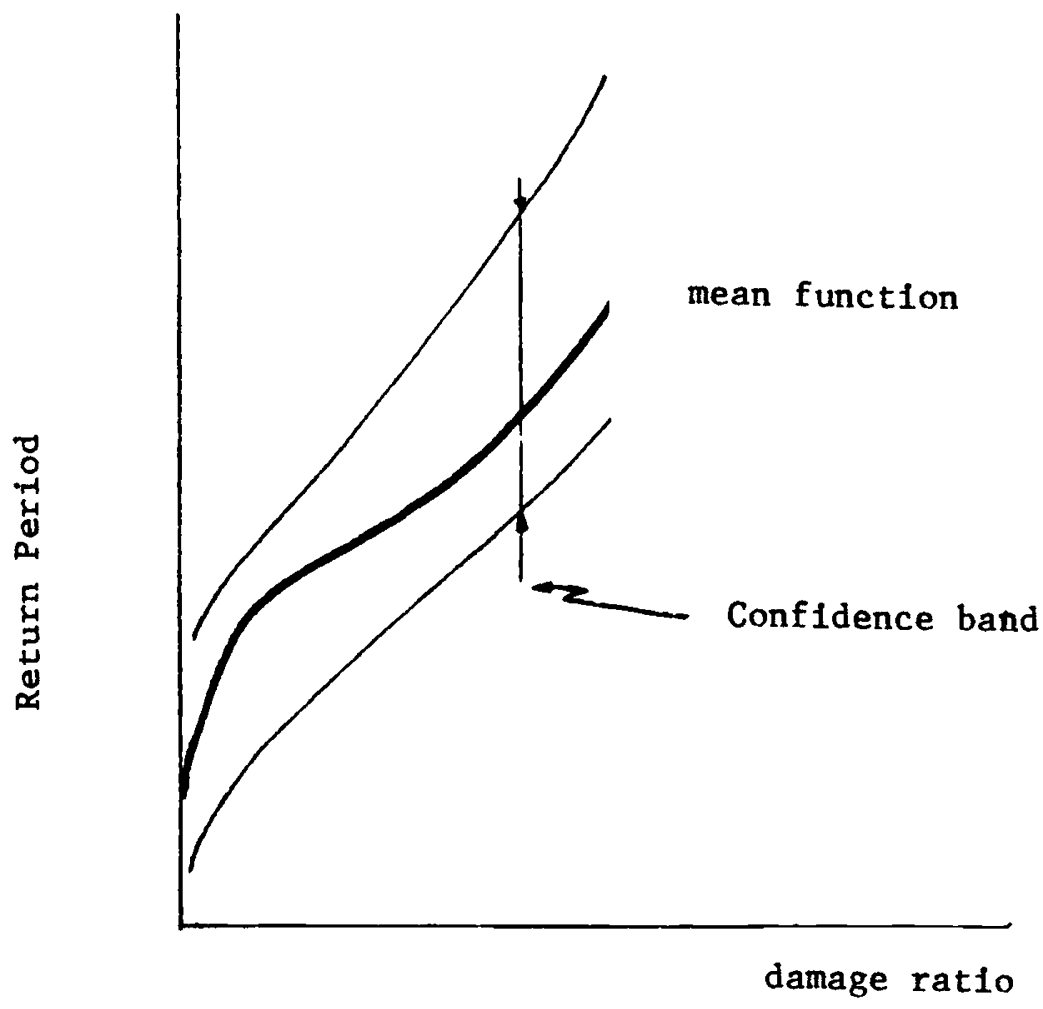

Figure 4.5

of $0.35 \%$ an area with very high landslide potential will be affected by landslides over $30 \%$ of its area and $30 \%$ of the building population for this particular area will suffer landslide damage. A relation between damage to structure and landslide is too complex to be analyzed in a general sense. A gross approach might be to shift by one intensity the damage ratio.

Technical reports usually rate liquefaction potential as high and low-moderate. When data are available, procedures developed by Seed and Idriss [1970] and Seed [1979] provide a simplified approach for determining the liquefaction potential. The data necessary to apply the method are :

- magnitude of the earthquake;

- peak ground acceleration;

- depth to water table;

- standard penetration test results at different depths. 


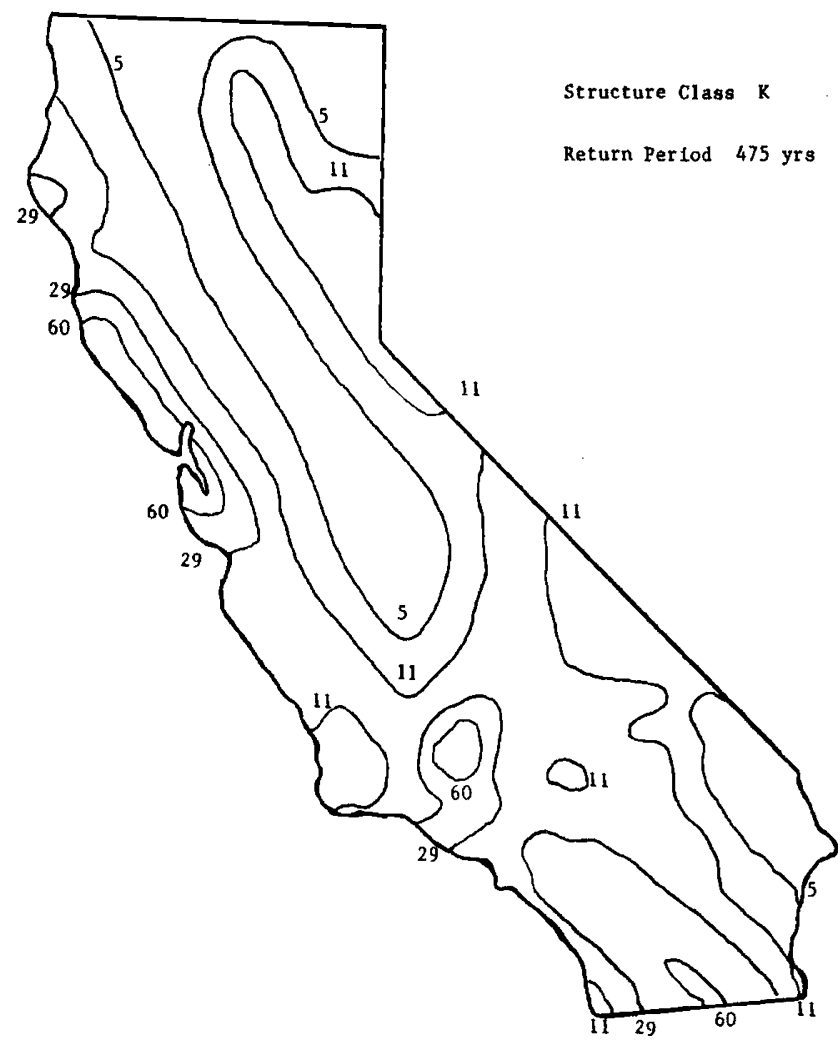

Figure 4.6: Example of iso earthquake damage ratios for a given confidence level

For the given data above and a given PGA, the percentage of the area which will undergo liquefaction (high or low) can be assessed (Mortgat [1983]). Damage ratio can be crudely estimated as $10 \%$ for low liquefaction (small deformation) and $35 \%$ for high liquefaction (large deformation). Other studies have estimated global damage ratio at $20 \%$ under liquefaction (Scawthorn [1981]). Those values are given as examples and should not be used without specific studies.

Combination of ground shaking hazard with landslide and liquefaction hazards give curves similar to Figures 4.5 and 4.6. Other hazards such as fires, dam failure and alike can be incorporated in the overall seismic risk analysis. However large uncertainties exist in such analysis.

\subsection{Tariff and probable maximum loss}

In general, seismic risk due to primary hazard is considered. The effects of secondary hazards are often considered as marginal. However this may not be true and geological hazard maps should be used in any preliminary study to asses their importance. 
Isodamage maps as illustrated in Figure 4.6 present the advantage that the level of confidence is constant. Such maps can be used to define tarrif zones for each type of structure. Each zone is defined so by a curve as in Figure 4.5 for a given level of confidence and expected yearly damage ratio may be estimated. This estimate is based on the assumption of an uniform distribution of every type of structures over the seismic region.

The estimation of loss exposure zones and aggregate loss zones requires the assessment of the worst probable seismic event, with a corresponding return period, the vulnerability analysis of all the types of structures, the amount of exposures insured as well as the location of the exposures.

Uncertainty on the assessment of the worst probable event must be estimated in such an analysis, especially in regions with low seismicity where buildings are seismically vulnerable so great damage can occur, even for moderate earthquakes.

Uncertainty on estimation of damage ratio can be estimated with the help of the information given in Appendix A but sound engineering judgement is still of the utmost importance.

The amount of exposure may be assumed deterministically, however uncertainty might be necessary to estimate since the policies may not record all relevant informations (type of structures, location, particular insurance policy clauses and alike).

The probable maximum loss is computed by assuming that the loss of the buildings insured in the same zone is equal to the sum of the loss of every building insured in this region. This will give an upper bound on the loss estimation.

Several problems are relevant to the determination of the probable maximum loss, namely: hazard analysis (worst probable event), vulnerability analysis, exposure and location. The determination of the exposure and location are specific problems relevant to the insurance since the uncertainty on this estimation depends in great part of the insurance book keeping. It is suggested that in some case this is the most important factor to take into account.

\section{Dynamic model}

The use of isoacceleration (isointensity) and/or isodamage maps, as defined in sections 3 and 4 , along with the estimation of expected damage ratios are convenient and adequate for estimating premiums over a long period of time. However, they do not estimate the dynamic process of the occurrence of events of different magnitudes.

Recent studies in Seismology have shown that correlations between earthquake recurrence intervals and the size of the events exist. Semi Markov models can be applied to consider the non random character of earthquake location, size and timing. Amount of energy released, and stress accumulation, are some of the parameters used in the forecasting of the earthquake occurrences.

Time dependent seismic hazard models can be incorporated in the study of an earthquake portfolio as briefly described below. 
Let $-X_{o}$ the initial reserve.

- $L_{o}, L_{1}, \ldots L_{k}$ the risk process which considers all the probable possibilities of losses in the time period $0,1, \ldots k$.

- $P_{o}, P_{1}, \ldots P_{k}$ the premium process.

It is desirable to estimate the state process $X_{o}, X_{1}, \ldots X_{k}$ defining the insurance state (reserve for example) at time $0,1, \ldots k$ and the corresponding probabilities of the different possible states (in particular the probability of ruin) for each time period. Figure 5.1 is a schematic representation of the state variables previously described.

Pentikainen [1979, 1981] introduced the use of stochastic dynamic programming as a technique for forecasting limits within which the insurance business will flow in time. This methodology is useful for management policy and can be applied not only to an earthquake portfolio but to several portfolios. Solvency problem, reinsurance consideration, reserve allocations can be treated this way.

The general goals of an insurance company are (Beard et al [1977]) :

a) solvency;

b) maximization of profits ;

c) expansion of the company ;

and a general model must include these aspects mentioned. Symbolically, a stochastic model can be described as :

$X(t+1)=f[t, x(t), Z, r(t)]$

$X[X(0), X(1), \ldots X(t)]$ is the state process.

$Z$ a given strategy.

$r(t)$ a " noise" process e.g., a random process characterizing the amount of claims.

$t$ time period.

For a given strategy $Z$, the state $X(t)[t=0,1, \ldots n]$ can be calculated when $X_{o}$ is given. As $r(t)$ is a stochastic process, a simulation technique can be used to obtain $X(t)$ and its variations. Figures 5.2 and 5.3 show an example of such analysis results. The risk reserve $X$ defines the state process and the strategy is to decide the amount of the initial reserve. Fluctuations of the reserve and probability of ruin can then be evaluated over time for example.

Earthquake insurance with large potential catastrophic losses does not follow conventional methods such as expected losses for a given return period. Solvency problem and investigation of optimal strategies can be approached by means of stochastic dynamic programming models which forecast limits within which the insurance state will follow. This methodology can be applied to the study of portfolios other than earthquake coverage. However, the seismic hazard and vulnerability analyses are of prime importance because too large uncertainties will yield useless results.

Finally the relative importance of earthquake losses to others natural hazard losses must be assessed in such decision making. 


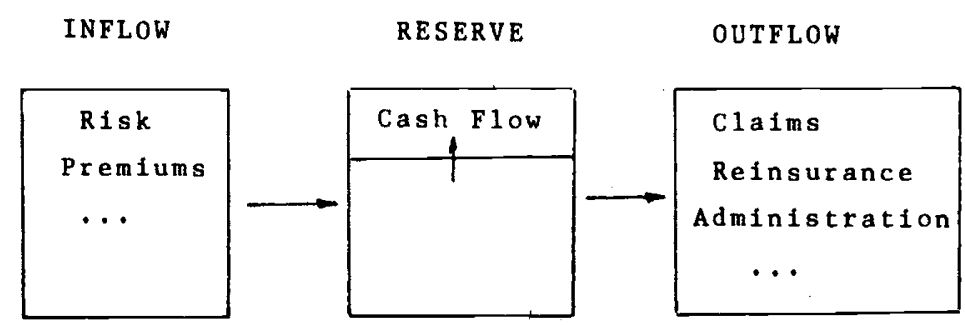

Figure 5.1

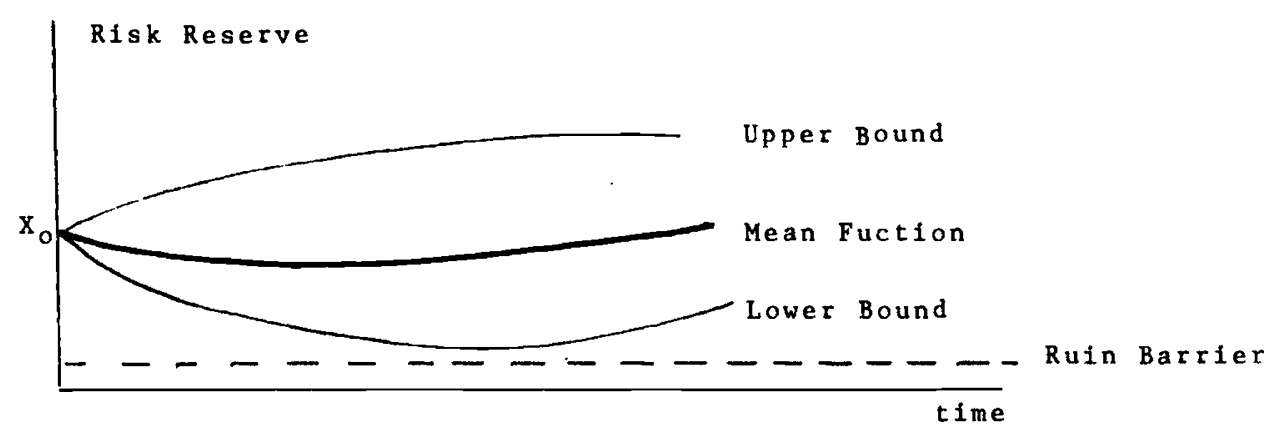

Figure 5.2 : Fluctuation of risk reserve over time

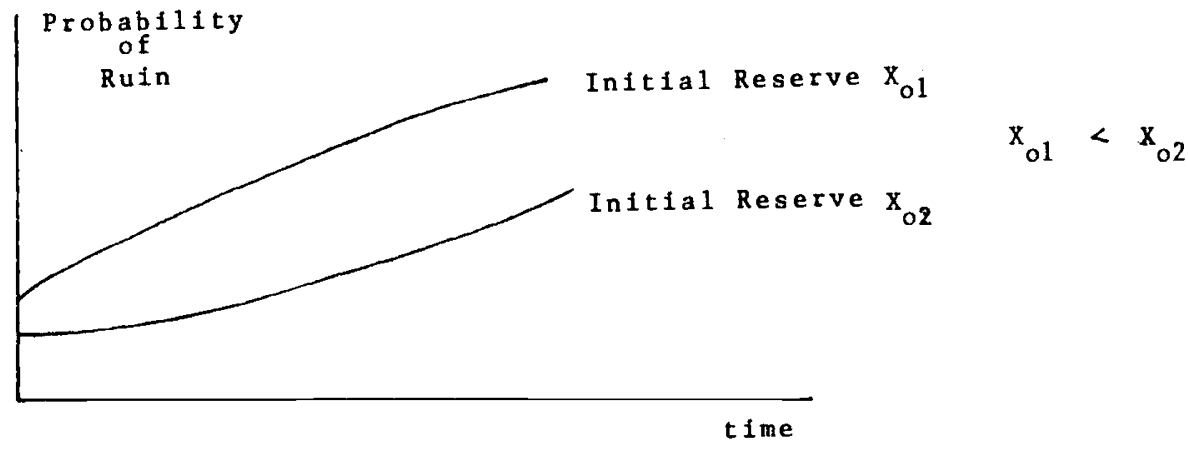

Figure 5.3 


\section{Conclusion}

A review of the different methods used in treating seismic risk analysis for insurance purposes has been presented. Many uncertainties exist in such estimations. However, they can be estimated systematically and convolved together to obtain a consistent level of confidence on the evaluation of losses.

Vulnerability analysis as defined in the introduction is an important aspect of the risk analysis. However the lack of understanding of the mechanism of damage results in incomplete and inaccurate methodologies and great care must be applied before using any of these methods.

Seismic hazard analysis is of primary importance in a risk analysis and each uncertainty should be taken into account to be able to define the limits of the analysis. A sensitivity analysis must be performed to point out the most important factors to investigate in the overall analysis.

An approach to reduce the expected loss in a seismic region is to reduce the vulnerability. Several mitigations procedures exist but the implications of each one must be weighted and their applicability evaluated. Insurance is one available indirect mitigation on an international, national and regional level.

\section{REFERENCES}

ALGERMISSEN, S. T., STEPP, J. C., RINEHART, W. A., ARNOLD, E. P. [1969]: " Studies in Seismicity and Earthquake Damage Statistics, Appendix B ", U.S. Department of Commerce and Geodetic Survey, Washington, D.C.

BEARD, R. E., PENTIKAINEN, T., PESONEN, E. [1977] : Risk Theory: The Stochastic Basis of Insurance, Chapman and Hall, London.

CHICK, A.C. [1934]: "Discussion of Fundamental Factors Involved in the Underwriting of Earthquake Insurance ", Bulletin of the Seismological Society of America, Vol. 23, pp 385-397.

DONG, W. M., SHAH, H. C., BAO, A., MORTGAT, C. T. [1983] : “Utilization of Energy Flux, Seismic Moment and Geologic Information in Bayesian Seismic Hazard Model - Some Influential Aspects ". Submitted for publication.

FREEMAN, J. R. [1932] : Earthquake Damage and Earthquake Insurance, McGraw-Hill, New York.

LIU, B. C., HSIEH, C. T. et al. [1979]: “Earthquake Risk and Damage Functions, An Integrated Prepardness and Planning Model Applied to New Madrid ", Midwest Research Institute, Kansas City, MO.

MORTGAT, C. P. [1983] : “Probabilistic Seismic Hazard Analysis and Damage Assessment ”, Tera Corporation, Berkley, CA.

MUNICH REINSURANCE COMPANY [1976]: “Guatemala '76 Earthquake of the Carribean Plate ", Munich. 
PENTIKAINEN, T. [1979]: “Dynamic Programming, An Approach for Analyzing Competition Strategies", ASTIN, Vol 10.

PENTIKAINEN, T., RANTALA, J. [1981]: "Evaluation of the Capacity of Stochastic Dynamic Programming ", ASTIN, Vol 12.

SAUTER, F., SHAH, H. C. [1978] : "Estudio de Seguro Contra Terramoto ”, Instituto National de Seguro, San Jose, Costa Rica.

SCAWTHORN, C. [1981]: “Urban Seismic Risk, Analysis and Mitigation ", Ph.D. thesis, Kyoto University, Japan.

SEED, H. B., IDRISS, I. M. [1970] : “A Simplified Procedure for Evaluating Soil Liquefaction Potential ", EERC, report No. 70-9, Berkeley, California.

SEED, H. B. [1979] : "Soil Liquefaction and Cyclic Mobility Evaluation for Level Ground During Earthquakes", Journal of the Geotechnical Engineering Division, ASCE.

STEINBRUGGE, K. K., McClURE, F. E., and SNOW, A. J., [1969]: "Studies in Seismicity and Earthquake Damage Statistics, Appendix A", U.S. Department of Commerce Coast and Geodetic Survey, Washington, D.C.

WIGGINS, J.H. [1981]: "Earthquake Hazard and Risk Mitigation ”, J. H. Wiggins Company, Redondo Beach, Ca.

WIGGINS, J. H. [1981] : "Factors Affecting Earthquake Insurance", Presented Feb. 1981 to the American Insurance Association, Atlanta, GA. 